\title{
LEVANTAMENTO DAS TRILHAS E CARACTERIZAÇÃO DOS VISITANTES DO MORRO DO CAMBIRELA, MUNICÍPIO DE PALHOÇA, SC
}

\author{
Anastácio da Silva Júnior ${ }^{1}$
}

\section{Resumo}

Este trabalho foi realizado com o propósito de levantar e caracterizar as trilhas e visitantes do Morro do Cambirela (922m), Município de Palhoça, próximo de Florianópolis/SC, no Parque Estadual da Serra do Tabuleiro (PEST). Foi elaborado um diagnóstico para caracterizar os visitantes, suas preferências e percepções, subsidiando a avaliação dos impactos da visitação pública. As informações sobre os usuários e a visitação foram obtidas por meio de formulários (120) durante os meses de setembro e outubro/2010 e entre maio e setembro/2011, aproveitando-se o maior fluxo de visitação. Verificou-se que a trilha 1, por ser a mais utilizada por $62 \%$ dos visitantes, se encontra em pior estado de conservação e a área de acampamento está muito degradada. Isso se explica, em parte, pela falta de gestão de controle dos acessos e manutenção da área. As trilhas 2 e 3 estão em melhores condições de uso. O estudo sobre o perfil dos visitantes mostrou que a maioria reside na grande Florianópolis e possui alto nível cultural. Alguns estudos mostram que quanto maior a condição cultural do visitante melhor a conservação da área natural visitada, o que contradiz a realidade verificada no Morro do Cambirela. Os impactos causados pela ação antrópica foram: a grande presença de lixo nas trilhas, principalmente na trilha 1 e na área de acampamento; a presença de muitos restos de fogueiras; pichações nas pedras; cortes de facão nas árvores; ravinamento e raízes expostas nas trilhas e destruição da vegetação na área de acampamento.

Palavras-chave: Uso público; trilhas; Morro do Cambirela.

\begin{abstract}
The aim of this study was identify and characterize the trails and visitors in the Cambirela Hill (922m), locality of Palhoça, near Florianópolis / SC, State Park of Serra do Tabuleiro (PEST). The visitor profile, their preferences and perceptions, was evaluated to help in studies of the impacts of public visitation. Information about users and visitation were obtained through questionnaires (120) during the months of September and October, 2010 and between May and September/2011, taking advantage of the increased flow of visitors. It was observed in trail ' 1 ', the most used by $62 \%$ of visitors, the worst condition and camping area is too degraded. Trails ' 2 ' and ' 3 ' are better able to use. The study about the profile of visitors showed that the majority lies in Florianopolis and has high cultural level. The study about the profile of visitors showed that the majority lies in Florianopolis and has high cultural level. Some studies show that the greater the cultural condition, better conservation of natural area visited, which contradicts the reality seen in the Cambirela hill. The impacts caused by human action were: the large presence of trash on the trails, especially on the trail "1" and the camping area, the presence of many remains of fires, graffiti on the stones, cuts in trees, ravine and exposed roots on the trails and destruction of vegetation in the camping area.
\end{abstract}

Keywords: Public use; trails; Cambirela Hill.

\footnotetext{
${ }^{1}$ Professor do Instituto Federal de Santa Catarina - IFSC. E-mail: anastac@ifsc.edu.br
} 


\section{Introdução}

O Morro do Cambirela (922 m) fica localizado no Município de Palhoça, próximo de Florianópolis, dentro do Parque Estadual da Serra do Tabuleiro (PEST), sendo esta a maior Unidade de Conservação no Estado de Santa Catarina (Figura 01). O parque ocupa aproximadamente $1 \%$ do território catarinense, com área de 87.405 hectares. Foi criado através do Decreto 1.260/1975 e abrange áreas de nove municípios: Florianópolis, Palhoça, Santo Amaro da Imperatriz, Águas Mornas, São Bonifácio, São Martinho, Imaruí, Garopaba e Paulo Lopes. Engloba também as ilhas de Fortaleza/Araçatuba, Ilha do Andrade, Papagaio Pequeno, Três Irmãs, Moleques do Sul, Siriú, Coral, dos Cardos e a ponta sul da Ilha de Santa Catarina (SANTA CATARINA, 1975).

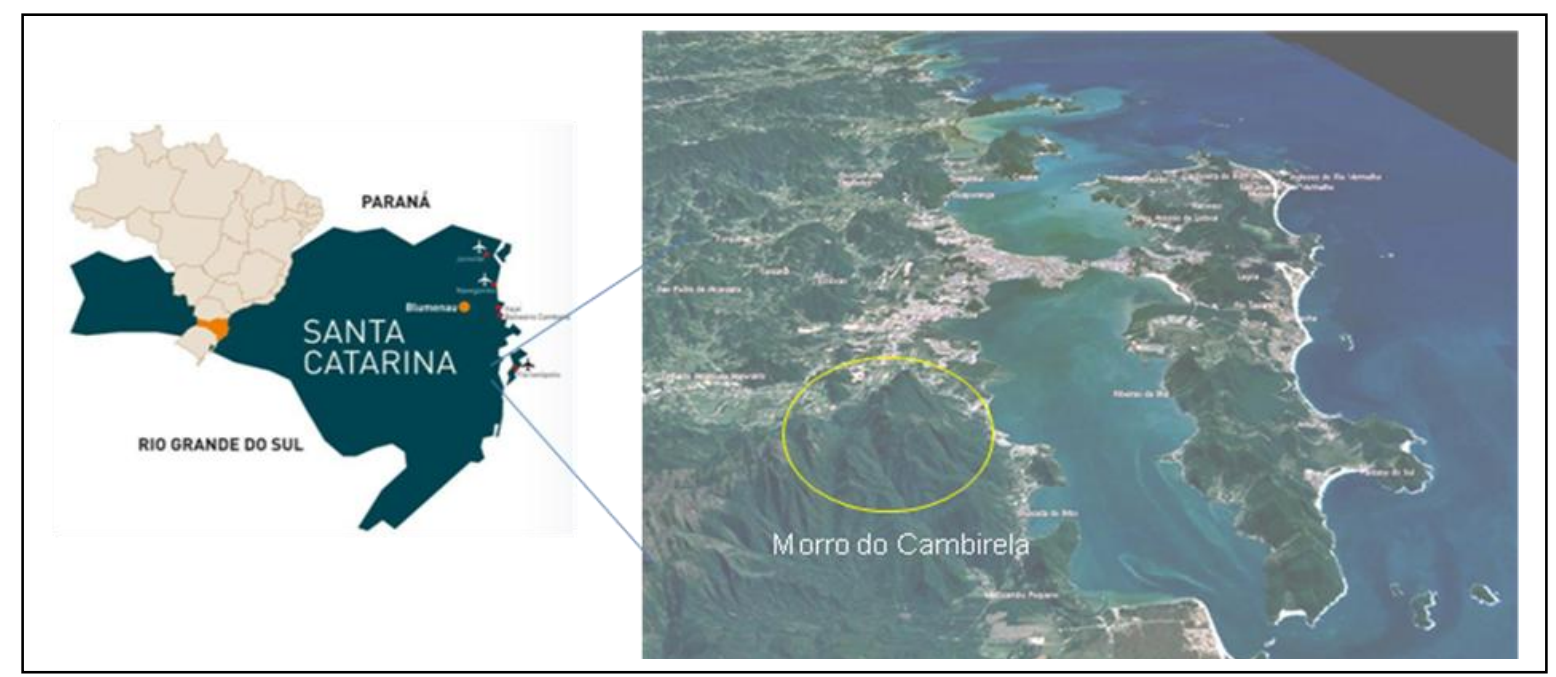

Figura 01. Morro do Cambirela e Ilha de Santa Catarina Fonte: Google Earth (2011).

A escalada do Morro do Cambirela se inicia por trilhas de acesso que passam por propriedades particulares ou em seu entorno. Trata-se de um percurso de, aproximadamente, três horas transpondo áreas de mata, vegetação rasteira até atingir o cume da montanha. Os problemas com despejo de resíduos sólidos pelos frequentadores da área são observados ao longo das trilhas e nas áreas de acampamento. Por ser relativamente perto dos centros urbanos, acesso fácil e nível difícil, vários excursionistas se aventuram na escalada do morro. Muitos dos visitantes são de regiões bem próximas e praticam caminhadas (trekking) e escaladas. Enquanto uma grande parcela dos visitantes não demonstra consciência ambiental e despeja seus resíduos ao longo das trilhas, os praticantes regulares de esportes apresentam um comportamento mais racional, mas este grupo constitui minoria.

Mesmo integrando área de uma Unidade de Conservação estadual, o controle ambiental e dos acessos no Morro do Cambirela é bastante precário.

Objetivos

$\checkmark$ Mapear as trilhas e verificar o seu estado de conservação.

$\checkmark$ Caracterizar os visitantes e sua percepção ambiental. 


\section{Justificativa}

A importância das trilhas remonta ao início da humanidade e, por milênios, elas foram o modo de deslocamento e ligação entre diferentes povos. Zeferino e Carson (2005) relacionam as trilhas com a própria história e o mundo das relações, pois, um dia, todas as comunidades tiveram suas trilhas e caminhos. Muitos desses traçados viraram estradas e outros se esvaíram no esquecimento da nova gente que se assentou em diferentes lugares. As trilhas formam um legado que não se pode esquecer, portando deve-se garantir a continuidade de seu desfrute pela presente e pelas futuras gerações.

No Brasil, segundo Bueno (1998), a mais antiga trilha de que se tem registro é a do Peabiru, que ligava o litoral catarinense e o paulista por dois ramais que se uniam no centro do Paraná à Serra do Potossi no Peru. Esta trilha era utilizada por povos incas e indígenas brasileiros antes do descobrimento.

Atualmente as trilhas são utilizadas nas mais diferentes atividades de contato com a natureza. Conforme Vashchenko (2006), este uso acontece como atividade turística em áreas silvestres que, conforme as atividades praticadas, pode ser chamado de ecoturismo, turismo de aventura, turismo rural, histórico-cultural ou técnico-científico. As atividades em regiões montanhosas fazem parte do turismo de aventura e são denominadas de montanhismo. Diante do estado crítico das nossas unidades de conservação e suas trilhas, como cita Andrade (2000), é compreensível que poucos trabalhos relativos ao assunto tenham sido publicados e, entre esses poucos, praticamente a maioria enfoca apenas a possibilidade de trilhas de interpretação em unidades de conservação. Este tipo de trilha tem caráter educacional e pode ser definido como sendo um percurso em um sítio natural que consegue promover um contato mais estreito entre o homem e a natureza. Consiste num instrumento pedagógico importante que possibilita o conhecimento de fauna, flora, geologia, geografia, dos processos biológicos, das relações ecológicas, do meio ambiente e de sua proteção. Ainda, segundo Andrade (2000), a real implantação de unidades de conservação e sistemas de trilhas é atualmente de extrema importância. Ao longo dos últimos anos, a sociedade, de uma forma geral, vem pressionando os governantes para que estes dediquem maior atenção às áreas naturais e que realizem sua efetiva implantação e conservação. Esse processo, aliado ao incremento do ecoturismo, faz crer que num futuro próximo estas áreas serão organizadas de forma mais adequada.

No Estado de Santa Catarina, a Serra do Mar e particularmente o Morro do Cambirela, é muito procurada para a prática turística, que consiste em alcançar os cumes das montanhas por meio de escaladas ou caminhadas. Para a prática do montanhismo, a abertura de trilhas é uma necessidade e elas passam pelas mais diversas situações de relevo, solo e vegetação, sendo que a pressão exercida pela prática de caminhadas causa um impacto diferenciado dependendo da condição existente. Por exemplo, algumas plantas são mais resistentes ao pisoteio que outras e solos menos desenvolvidos resistem menos ao processo de compactação e à erosão.

Entende-se, portanto, que há necessidade de racionalização do uso público no Morro do Cambirela. Para que isso ocorra, além de um profundo conhecimento do local a ser 
explorado, também deverá haver preocupação e consciência ambiental das pessoas que se utilizam do lugar para visitação turística e práticas esportivas.

\section{Procedimentos Metodológicos}

$\mathrm{Na}$ pesquisa, foram coletados dados sobre as características das trilhas e locais de acampamento do Morro do Cambirela e dos visitantes que as usam, buscando-se avaliar os danos causados à elas. A partir dos dados coletados e analisados, pôde-se chegar a determinadas conclusões que ajudarão no estabelecimento de diretrizes educativas para evitar que esses danos aumentem e tragam prejuízos para o desenvolvimento sustentável da região.

Trata-se de pesquisa empírica que codificou elementos mensuráveis de determinada realidade social dos visitantes do Morro do Cambirela, assim como os impactos da visitação. Os dados da pesquisa poderão contribuir para propostas de intervenção na realidade social, através de ações de Educação Ambiental, visando a diminuição dos impactos e a adequação do uso da área. É um trabalho original, pois pela primeira vez o Morro do Cambirela é contemplado com um estudo deste tipo, tendo como meta principal a compreensão das causas da sua degradação ambiental.

O estudo das trilhas foi realizado utilizando-se um aparelho GPS Garmin e apoio dos programas Google Earth e GPS TrackMaker, possibilitando o mapeamento dos traçados das mesmas.

A pesquisa de campo com os visitantes ocorreu entre os meses de abril e setembro/2011, com 12 excursões ao Morro do Cambirela. Nestes meses, tradicionalmente os mais frios do ano, a frequência é maior, pois em dias muito quentes tornam-se mais cansativos, além de maiores riscos com a presença de animais peçonhentos. Esse fato foi confirmado através de entrevista informal com moradores residentes nas redondezas, agentes da Fundação de Meio Ambiente do Estado de Santa Catarina (FATMA) e outros frequentadores. Como os excursionistas preferem os finais de semana (sábados e domingos), estes foram escolhidos para aplicação dos formulários. Foram aplicados 120 formulários, dos quais 92 respondidos em campo (Figura 02) e os 28 restantes respondidos pela internet, via redes sociais. O formulário de pesquisa buscou elementos para caracterizar o perfil dos visitantes e suas percepções sobre o ambiente visitado, sendo aplicado de forma aleatória às pessoas encontradas no local. Para a realização da pesquisa foi necessário uma autorização especial da FATMA. 


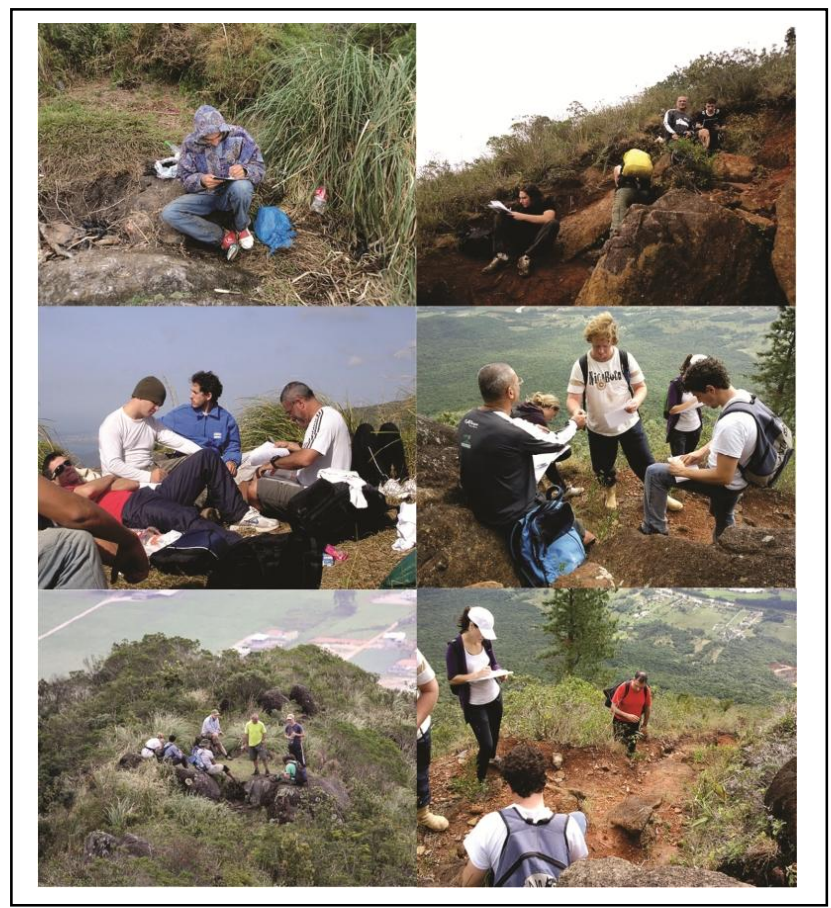

Figura 02. Aplicação dos formulários aos visitantes do Morro do Cambirela Fonte: Pereira (2011).

\section{Trilhas do Morro do Cambirela}

Várias são as trilhas que levam ao cume do Morro do Cambirela. As principais e mais utilizadas são denominadas de trilhas 1, 2 e 3 e podem ser visualizadas na Figura 03. Elas estão dentro da Zona de Uso, de acordo com o Mapa de Zoneamento (SOCIOAMBIENTAL, 2002).

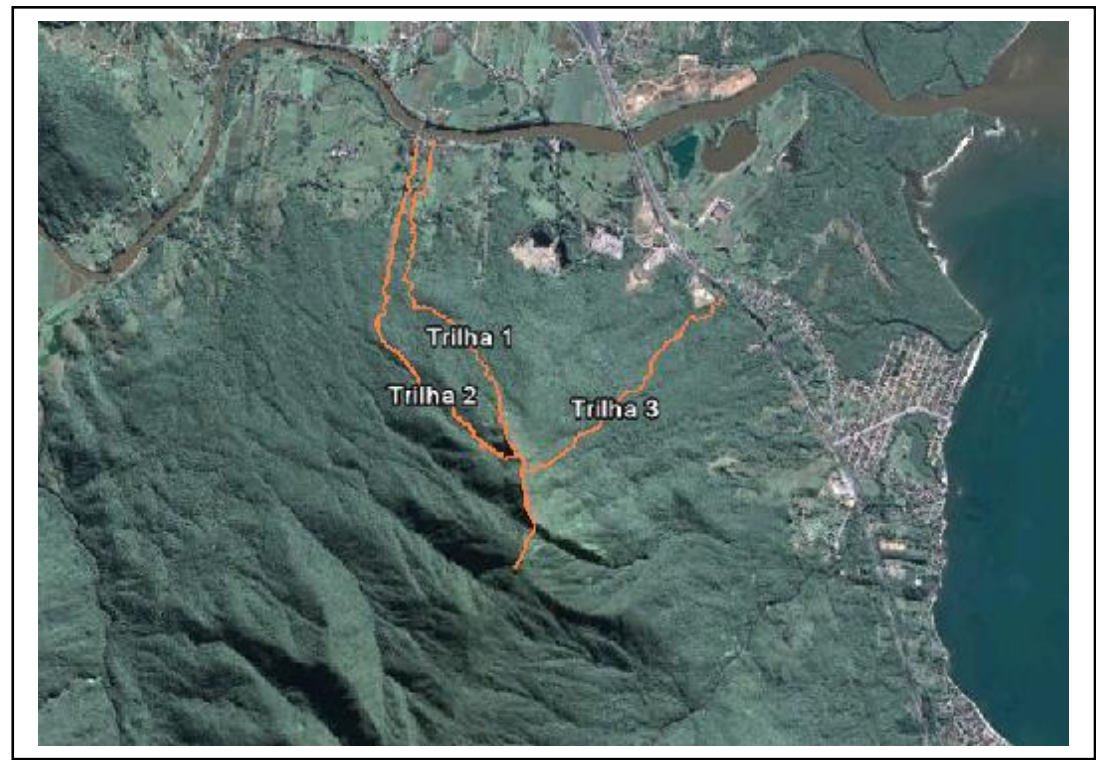

Figura 03. Mapeamento das trilhas do Morro do Cambirela Fonte: Google Earth (2011) 
A seguir, a descrição geral de cada uma das trilhas.

a) Trilha 1 - A via de subida segue pela aresta norte do Cambirela, inicia na estrada geral da Guarda do Cubatão, ou Rua Jacó Vilain, cruzando com a Rua Dezesseis, seguindo plana por cerca de 500 metros e depois começa a inclinar de forma quase constante. Depois da primeira porteira, existe uma placa indicativa do caminho, pois através das propriedades particulares é muito fácil errar o acesso. Uma vez na trilha, sobe-se por uma canaleta de chuva com mato bem fechado por cerca de 30 minutos até uma fonte de água, para então retornar 10 metros e entrar na trilha principal. A subida é toda feita na mata até a cota $600 \mathrm{~m}$ e até lá, existe apenas uma bifurcação com o caminho correto à esquerda, já que, à direita, a subida é direta até uma rampa de rocha, mas segue por um terreno totalmente erodido e com pedras soltas. Os primeiros lances de corda começam pouco depois da cota 500 e dão acesso à base da parede que pode ser vista desde o começo da caminhada. Contorna-se um pouco a rocha e então se sobe por uma canaleta de uns 8 metros de altura, que normalmente tem uma corda esticada desde o topo. Depois disso o terreno é mais inclinado e a vegetação é rasteira, permitindo vista livre para o norte e leste. Segue-se por mais uns 20 minutos em valetas bem erodidas e então chega-se ao 'ombro', a saliência que se vê na aresta norte da montanha. Pouco acima é o local do acampamento principal e dali até o cume é uma caminhada rápida. Esta trilha é a mais problemática das três mapeadas, pois apresenta no seu início um processo de ravinamento e compactação de solo e, no seu final, próximo ao cume, movimentação de massa nas altas declividades, com muitos fragmentos de rocha soltos com grande risco aos usuários. Além disso, o trecho vertical com corda fixa, sujeita às intempéries e em precárias condições de uso, também oferecem grande risco aos usuários.

b) Trilha 2 - A via de subida segue pela aresta noroeste do Cambirela, inicia na estrada geral da Guarda do Cubatão, ou Rua Jacó Vilain, cruzando com a Rua Quinze. A partir da estrada, percorre-se 1,5 km por dentro de propriedades particulares, cercas, criações de gado e charcos alagados. Até esse ponto, a trilha é bem aberta, praticamente plana, passando pelas pastagens na base da montanha e, a seguir, encontram-se trechos de bambuzal onde começa fechar e adentrar na floresta. Já em mata fechada, a trilha começa ganhar inclinação e, após uma hora, até um lance de corda de aproximadamente 6 metros de altura, termina em uma borda de precipício com uma rocha um pouco delicada, bem estreita e forrada de mato. Neste ponto existem vários trechos de pedras soltas e uma única bifurcação que segue à esquerda. Esta trilha ganha altitude mais rapidamente no seu final e é praticamente toda dentro da mata, seguindo pelo leito de um rio, normalmente seco. O final da trilha 2 , também chamada de trilha da cachoeira seca, está em numa rampa de barro e pedras bem inclinadas, na cota de 680 m, onde se encontra com a trilha 1 antes do 'ombro', mostrado na Foto 2, e segue até o cume pelo mesmo caminho. Esta trilha é a que apresenta as melhores condições de uso, apesar de não ter sido planejada adequadamente. Nos trechos iniciais da trilha, em relevo suaveondulado não apresenta maiores problemas de erosão. À medida que a encosta se torna mais íngreme, em relevo montanhoso, a trilha segue pelo fundo de um vale sobre rochas com 
muitas raízes expostas, em terreno úmido e escorregadio, sendo este o fator de maior risco aos usuários.

c) Trilha 3 - A via de subida segue pela aresta leste do Cambirela, pela BR 101, no km 222. Esta trilha, em seu trecho inicial está inserida num relevo suave-ondulado, apresentando em grande parte processo de ravinamento. Após a saída da BR 101, caminha-se por cerca de $600 \mathrm{~m}$, até entrar na mata. Em seguida, em relevo montanhoso entra-se em terreno mais íngreme, sendo necessário, em praticamente toda a subida, o apoio das mãos com médio a grande risco para usuários inexperientes. No decorrer do caminho encontram-se muitas fontes de água corrente e pequenas cascatas. A trilha 3 possui duas cavernas, eventualmente usadas para acampamento, uma no meio da trilha, dentro da floresta (caverna 1), e outra no final da trilha (caverna 2), onde acaba a mata fechada. Esta trilha apresenta a maior inclinação entre as três estudadas e se ganha muita altitude rapidamente. Apesar da dificuldade imposta pelo terreno inclinado é a trilha mais curta e rápida. Na cota de $750 \mathrm{~m}$, a trilha sai da floresta, acima da área de acampamento e se encontra com as trilhas 1 e 2 seguindo até o cume. A composição do solo litólico, segundo Pimenta e Soldatelli (2007), apresenta muitos blocos de rochas e grande evidência de raízes expostas.

\section{Características dos visitantes do Morro do Cambirela}

O Morro do Cambirela, apesar de receber um grande número de visitantes, não possui qualquer dado referente às atividades em suas trilhas, mesmo estando dentro de um Parque Estadual. Observou-se que não há qualquer tipo de controle, fiscalização e sinalização das trilhas.

As amostras indicaram que a maioria dos visitantes reside na Grande Florianópolis, sendo que 69\% são moradores da Capital, 25\% dos Municípios Palhoça e São José, e apenas $6 \%$ são de outros Municípios.

O perfil etário dos visitantes amostrados é o seguinte: 21 a 25 anos (21\%), 26 anos a $30(19 \%)$ e 36 a 40 anos (14\%), indicando que a grande maioria é formada por jovens e adultos. Observou-se que $80 \%$ dos entrevistados eram do sexo masculino e $20 \%$ feminino. Dessa forma, os programas educativos devem ter enfoques diferentes, pois a interação entre homens e mulheres com o ambiente é diferente, devendo-se, então, promover programas educativos orientados para cada público no que se refere ao gênero.

No tocante às atividades profissionais, predominaram ligeiramente os autônomos ou empresários (27\%), seguidos pelos empregados da iniciativa privada (25\%), estudantes (23\%), funcionários públicos $(18 \%)$ e outras atividades $(8 \%)$.

Sobre o grau de escolaridade, $18 \%$ informaram possuir curso de pós-graduação e $48 \%$ com curso superior completo ou cursando universidades. Os que estão cursando ou completaram o nível médio, eram $27 \%$ e apenas $8 \%$, estão cursando ou completaram o nível fundamental.

Quando questionados sobre a experiência em trilhas, a maioria $(33,3 \%)$ respondeu que realiza essa atividade mensalmente. No caso específico das trilhas do Morro do Cambirela, a grande maioria $(63 \%)$ declarou ter experiência em trilhas, mas visitaram o Morro pela 
primeira vez. Questionados se gostariam de voltar ao Cambirela, 96\% dos entrevistados responderam que sim, indicando satisfação pela visita.

\section{Percepção ambiental do visitante e estado de conservação das trilhas}

Segundo Hanai (2005), esta percepção é um processo valioso, de extrema importância, que desperta a sensibilização do indivíduo em relação às realidades ambientais, propicia o alcance de diferentes níveis de conscientização sobre o meio ambiente e estimula ações relativas à conservação da natureza. Assim sendo, a opinião dos visitantes sobre as condições do Cambirela gera importantes informações para programas de monitoramento e essas informações proporcionam uma boa perspectiva sobre quais problemas são mais importantes para os visitantes e podem ser usadas para priorizar ações e estratégias de manejo.

Quanto à percepção do estado de conservação da trilha 1, utilizada por $62 \%$ dos visitantes, a maioria respondeu que concorda totalmente ou parcialmente que a trilha está em bom estado de conservação; 70\% dos entrevistados e uma pequena parcela acha que a conservação está em bom estado. Esse fato sugere que os visitantes não possuem um real entendimento do que seja uma boa manutenção e conservação de uma trilha, apontando um caminho inicial no processo de Educação Ambiental para o Cambirela. Essa trilha por ser a mais utilizada, logicamente apresenta o estado mais precário de conservação, sendo a mais problemática das três mapeadas, pois apresenta no seu início um processo de ravinamento e compactação de solo, como mostra a Figura 04a. Na faixa intermediária, tem-se o grande risco do trecho vertical com corda fixa em uma parede molhada, sujeita às intempéries e em precárias condições, oferecendo grande risco aos usuários.

No final da trilha, próximo ao cume, há movimentação de massa nas altas declividades, com muitos fragmentos de rocha soltos e com grande risco aos usuários, podendo ser observado na Figura 04b. Também foi constatada a grande quantidade de lixo deixado pelos visitantes ao longo do caminho e proximidades, nos pequenos córregos e árvores, conforme mostrado na Figura 05, sendo este o problema que mais chama a atenção do visitante e considerado o mais grave. Os visitantes não costumam perceber a gravidade dos demais impactos causados durante os percursos nas trilhas.
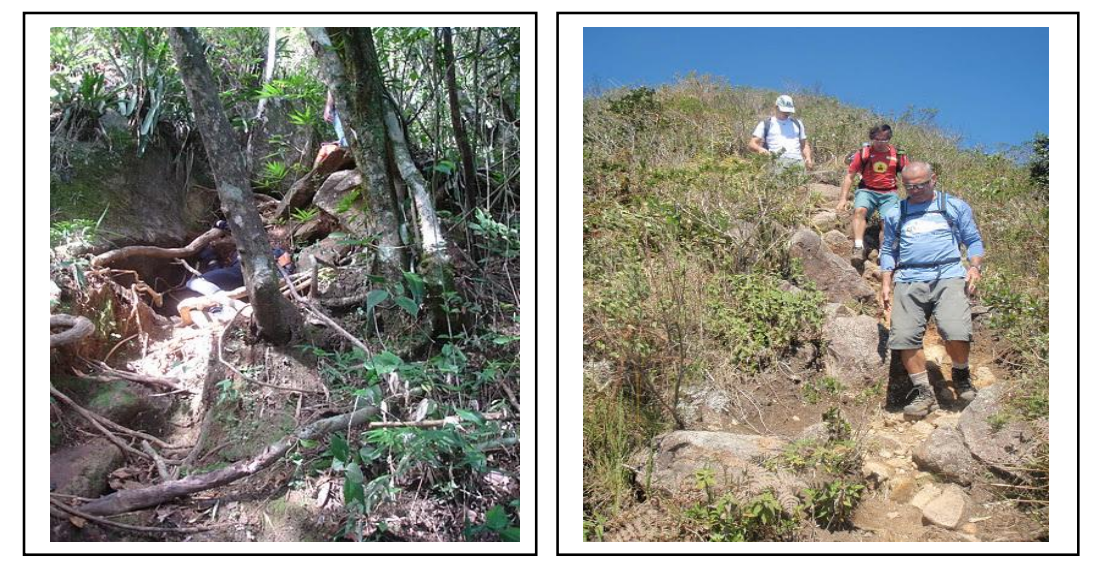

Figura 04. a) Ravinamento na trilha 1; b) Trecho com fragmentos de rocha soltos Fonte: Pereira (2011). 


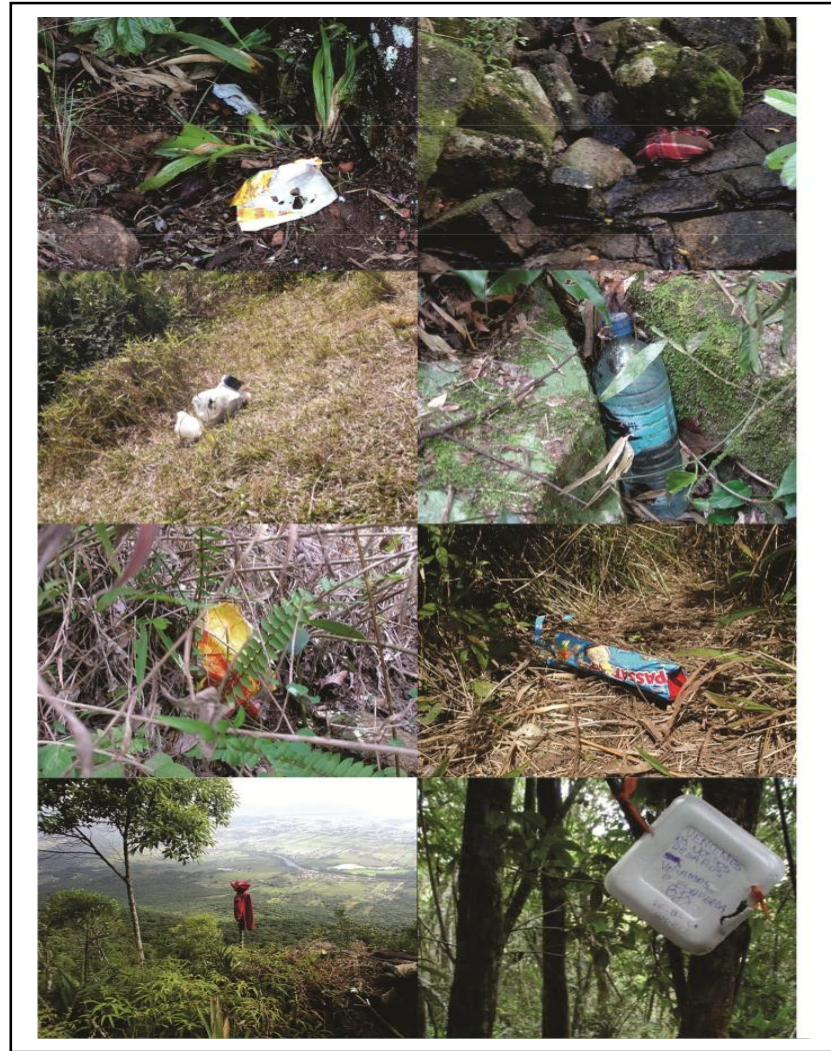

Figura 05. Lixo ao longo da trilha 1 Fonte: Silva Júnior (2011).

Ainda como observação da degradação na trilha 1, foram encontrados vários restos de fogueiras, fora da área usual de acampamento, pichações em pedras e cortes de facão nas árvores, como pode ser verificado na Figura 06.

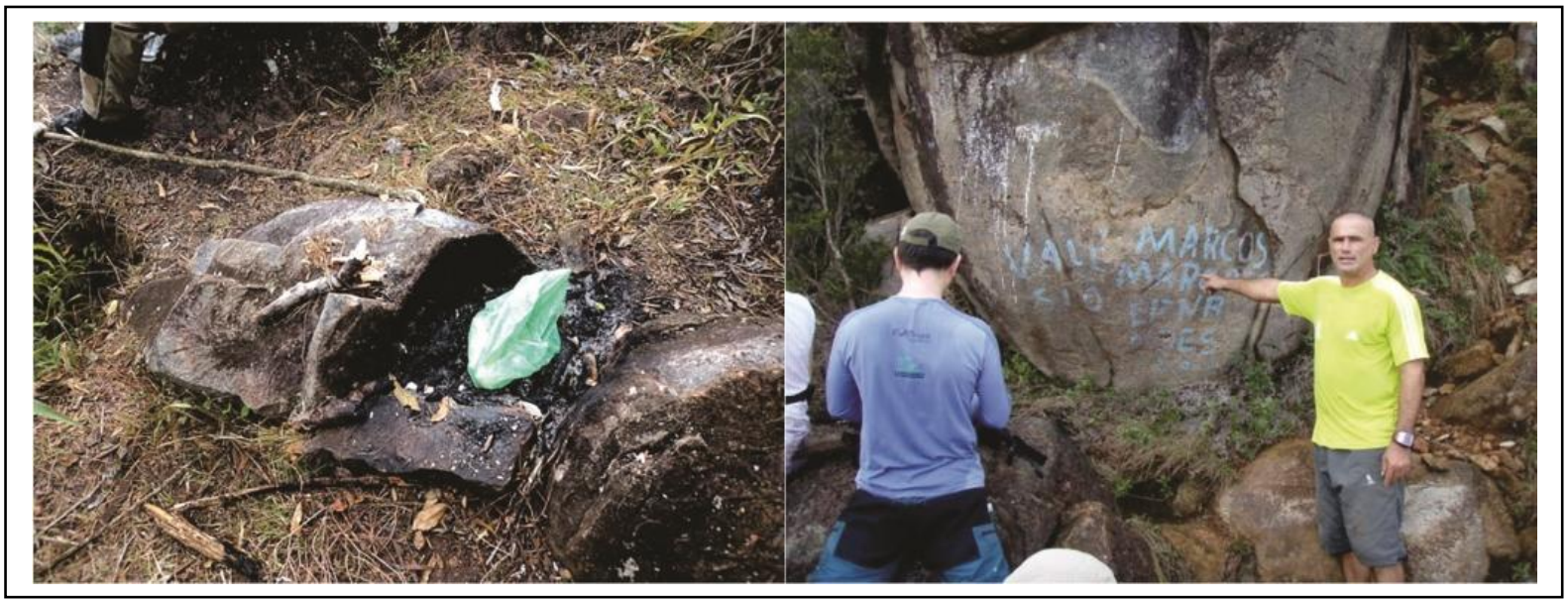

Figura 06. Restos de fogueira e pichação ao longo da trilha 1 Fonte: Pereira (2011).

Mesmo com o alto nível de escolaridade dos visitantes constatado nas entrevistas, os problemas ambientais nas trilhas são bem acentuados. Isso contraria o que já foi constatado em outras áreas de conservação, pois, segundo Vashchenko (2006), devido a maior parte dos 
visitantes em trilhas estudadas possuir experiência na prática do montanhismo e alto nível de escolaridade, os impactos tendem a ser menores.

$\mathrm{Na}$ trilha 2, utilizada por $18 \%$ dos visitantes, a percepção quanto ao estado de conservação, apontou uma distribuição similar entre as impressões dos visitantes. Apesar de que a maioria concordou parcialmente que ela está em bom estado de conservação, novamente se confirmou que o real entendimento sobre a conservação de uma trilha não é percebido pelos frequentadores do Cambirela. A trilha 2 é a menos utilizada, devido à dificuldade de encontrar e acessar seu início, pois exige a passagem por propriedades particulares, em meio à criação de gado e onde o acesso não é franqueado. Pela menor taxa de uso, esta trilha apresentou o melhor estado de conservação, com pouco lixo ao longo do caminho e vegetação mais preservada. Esta também possui um trecho vertical acentuado devendo ser utilizada uma corda para a escalada, o que representa certo perigo em sua utilização.

Para a trilha 3 , utilizada por $23 \%$ dos visitantes, a percepção quanto ao estado de conservação apontou para uma resposta positiva. A grande maioria, 76\%, concorda que ela se encontra em bom estado e, conforme verificado em campo, realmente a conservação desta trilha confirma a percepção dos visitantes. A trilha 3 é a segunda mais utilizada, mesmo com a dificuldade de encontrar o seu início, não existindo restrições à passagem pelo terreno que dá acesso ao lado da BR-101. Esta trilha apresentou bom estado de conservação, com pouco lixo ao longo do caminho. Esta, por ser a trilha de menor comprimento, apresenta a maior inclinação, ocasionando o aparecimento de ravinamentos e raízes expostas.

Em duas áreas de acampamento dentro das cavernas 1 e 2, da trilha 3, foi encontrado lixo e restos de fogueiras, como mostrado na Figura 07.

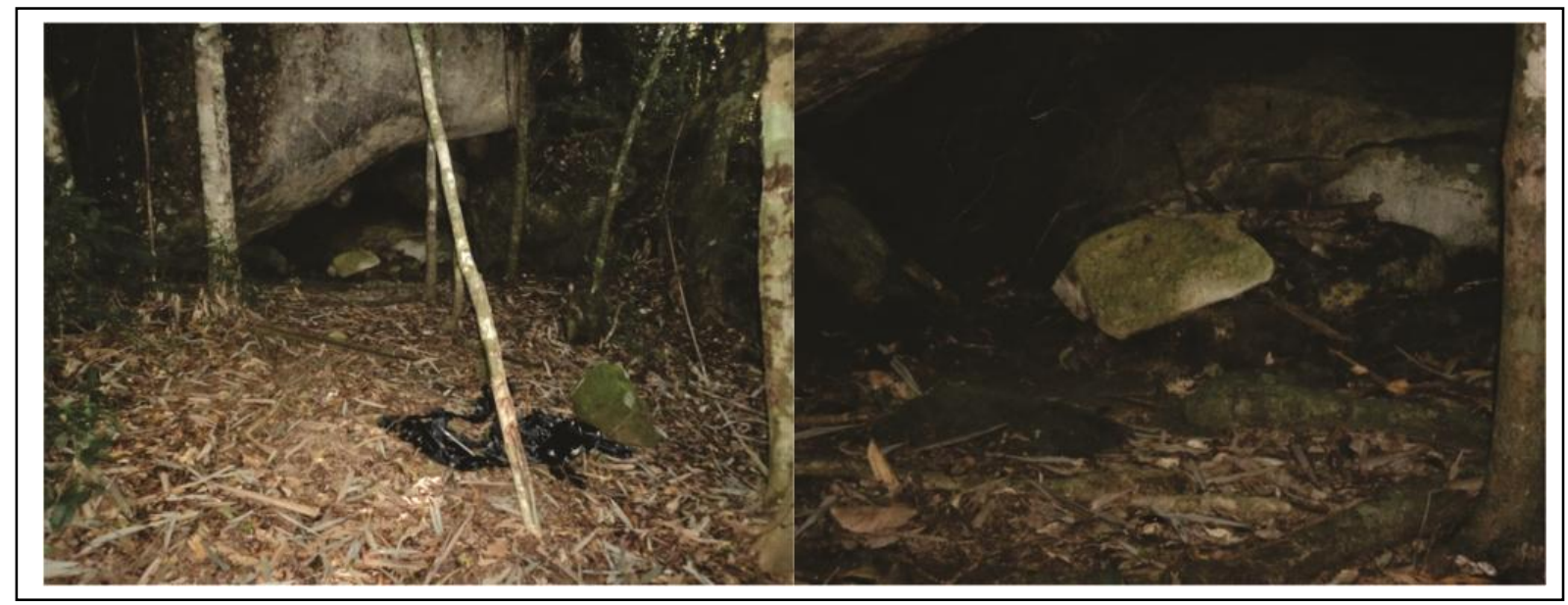

Figura 07. Lixo e resto de fogueira na caverna 1

Fonte: Dariva (2011).

Como nas demais trilhas, muitos visitantes quase sempre levam facões e é possível observar árvores com a superfície de seus troncos machucados por golpes ou com entalhes, 
como a árvore apresentada na Figura 8 Algumas se encontram sustentadas apenas pela metade do diâmetro de seus troncos.

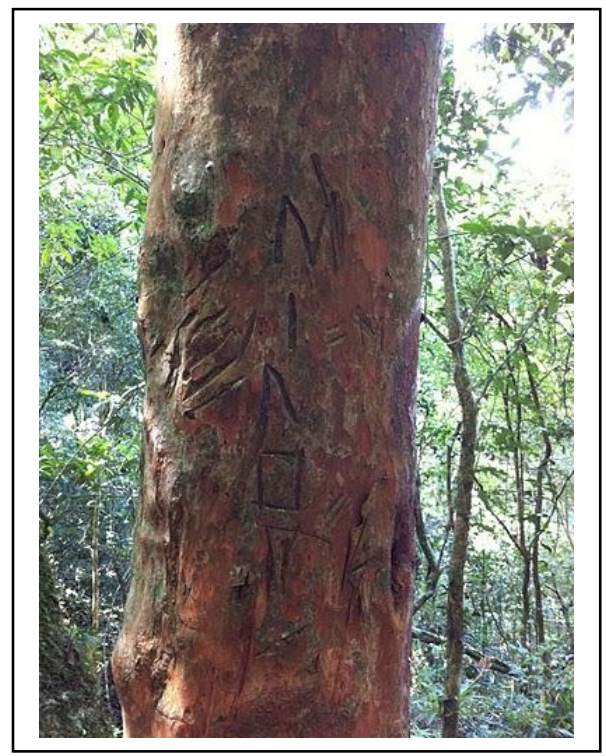

Figura 08. Cortes em árvore da trilha 3

Fonte: Dariva (2011).

Uma opção para diminuição do impacto causado pelo pisoteio seria a diminuição da intensidade de uso, com a melhor distribuição dos visitantes pelas trilhas existentes, ou ainda com a diminuição do número de passagens, com o controle de acesso. Essas opções são perfeitamente adaptáveis ao Morro do Cambirela, uma vez que todas as trilhas levam ao mesmo ponto, o cume, e possuem graus de dificuldades semelhantes.

A exposição de raízes que em vários trechos das trilhas estudadas é consequência de ações naturais e antrópicas. Segundo Viana (2008), além das correntes de água provocadas pelas chuvas, que podem provocar o afundamento de trilhas e desgaste do solo, colocando as raízes em evidência, em alguns casos, o próprio pisoteio ajuda a agravar a situação. Nesse sentido, para a preservação das trilhas, o monitoramento dessa variável deve ser realizado considerando-se a susceptibilidade do local a esse tipo de ocorrência. No caso especifico do Cambirela, é comum a ocorrência de raízes expostas, sendo estas utilizadas inclusive como degraus para facilitar a caminhada e ascensão nas trilhas. Diante disso, os locais com esse tipo de problema devem ser estudados e avaliados, conforme a realidade encontrada para cada local, possibilitando um planejamento para uso de determinados trechos.

Outro aspecto a ser considerado, é a capacitação dos condutores ambientais, sendo fundamental para minimizar a degradação em trilhas, através da adoção de uma conduta adequada que pode fornecer ao visitante melhores informações sobre o Morro do Cambirela e tornar o passeio mais agradável e seguro. Na região existem operadoras turísticas voltadas aos esportes de aventura que, eventualmente, promovem excursões ao Morro e estas devem ser estimuladas a capacitar de seus condutores. A FATMA, na condição de órgão gestor do Parque, deve efetuar o credenciamento e controle das operadoras e associações de condutores que têm a capacidade técnica de realizar atividades recreativas na unidade de conservação em 
que se encontra o Cambirela. Essa condição é essencial, segundo Barros (2003), para que seja possível a correção efetiva das situações indesejáveis nas trilhas e, principalmente, para manter uma condição ideal. Também se recomenda que a administração do parque realize um monitoramento para verificar se as ações de conservação, pois ao serem implementadas, produzem resultados satisfatórios. O monitoramento é fundamental para determinar se as ações de manejo resultam em melhora da situação atual sem alterar outras características do ambiente ou da experiência para o visitante.

\section{Conclusões}

Os estudos realizados nas trilhas do Morro do Cambirela indicam um bom potencial de aproveitamento da área para fins esportivos, turísticos e educacionais. Entretanto, existem deficiências administrativas que impedem um melhor aproveitamento e racionalização do uso público. Falta sinalização, orientação e práticas de manejo das trilhas, juntamente com ações educativas para diminuir os impactos causados. Estes impactos são decorrentes do pisoteamento somado às ações intempéricas que causam ravinamentos, além dos problemas de blocos de pedra soltos, principalmente nas áreas mais altas. Existem problemas com o despejo de lixo ao longo das trilhas e acampamentos que representam riscos de incêndios para toda a área.

O estudo sobre o perfil dos visitantes indicou o predomínio de pessoas oriundas da Grande Florianópolis, com alta escolaridade e maior poder aquisitivo, sendo que a maioria estava visitando a área pela primeira vez. Mesmo assim, os indícios da pouca consciência ambiental são grandes, tendo em vista os problemas com despejo de lixo, pichação e degradação da vegetação. Estes visitantes não demonstraram a percepção de que o pisoteamento e o ravinamento das trilhas são problemas ambientais do uso, apenas apontando o lixo como situação mais preocupante.

São urgentes ações políticas e administrativas por parte do governo estadual, e particularmente da FATMA, para se elaborar um planejamento da área, incluindo a sinalização, controle e manejo das trilhas, evitando-se futuros impactos sobre estas e riscos para os visitantes.

\section{Referências bibliográficas}

ANDRADE, W. J. - Manejo de trilhas. São Paulo: FEMESP, 2000.

BARROS, M. I. A. Caracterização da visitação, dos visitantes e avaliação dos impactos ecológicos e recreativos do planalto do Parque do Itatiaia. 2003. 121 f. Dissertação (Mestrado em Recursos Florestais)- Escola Superior de Agricultura Luiz de Queiroz, Universidade de São Paulo, Piracicaba, 2003.

BUENO, E. - Náufragos, traficantes e degredados: as primeiras expedições ao Brasil, 15001531. Rio de Janeiro: Objetiva, 1998. 204 p.

HANAI, F.Y. - Percepção e conscientização ambientais: alternativas para a preservação das cavidades naturais do Parque Estadual Turístico do Alto Ribeira (PETAR). 2005. Tese 
(Doutorado em Ciências da Engenharia Ambiental)- Centro de Recursos Hídricos e Ecologia Aplicada(CRHEA), Universidade de São Paulo, São Carlos. 2005.

PIMENTA, L.; SOLDATELI, M. Mapeamento das trilhas e dos impactos ambientais negativos no pico do Cambirela. Florianópolis: PEST-SC, 2006.

SANTA CATARINA - Decreto N/SETMA no 1.260 de 01 de Novembro de 1975. Cria o Parque Estadual da Serra do Tabuleiro. Diário Oficial do Estado de Santa Catarina. Florianópolis, v. 40, n. 10.358, p. 4-7, nov. 1975.

SOCIOAMBIENTAL CONSULTORES ASSOCIADOS. Parque Estadual da Serra do Tabuleiro / SC: Diagnóstico socioambiental elaborado para a Fundação Estadual do Meio Ambiente (FATMA). Florianópolis, 2002.

VASHCHENKO, Y. - Caracterização da trilha e o impacto do montanhismo nos Picos Camapuã e Tucum,Campina Grande do Sul-PR. 2006. Dissertação (Mestrado em Ciência do Solo)- Setor de Ciências Agrárias, Universidade Federal do Paraná. 2006.

VIANA, F. M. F. - Análise Ambiental da capacidade de carga antrópica nas trilhas do Circuito Janela do Céu - Parque Estadual do Ibitipoca, MG. 2008. 101 f. Trabalho de Conclusão de Curso (Especialização em Análise Ambiental) - Faculdade de Engenharia, Universidade Federal de Juiz de Fora, Juiz de Fora, 2008.

ZEFERINO, A. C.; CARSON, V. E. - Trilhas e caminhos da Ilha de Santa Catarina. Lagoa, Florianópolis, 2005. 